See discussions, stats, and author profiles for this publication at: https://www.researchgate.net/publication/324797413

\title{
Examining the feasibility of a Smart Region approach in the North West Atlantic and Borders Region of Ireland
}

Conference Paper · April 2018

DOI: $10.1145 / 3209415.3209512$

CITATIONS

2

5 authors, including:

Niall O'Brolchain

National University of Ireland, Galway

8 PUBLICATIONS 60 CITATIONS

SEE PROFILE

Lukasz Porwol

Digital Enterprise Research Institute (DERI)

36 PUBLICATIONS 175 CITATIONS

SEE PROFILE

Some of the authors of this publication are also working on these related projects:

Project Smart Places View project

Project ROUTE-TO-PA View project
READS

147

Adegboyega Ojo

National University of Ireland, Galway

165 PUBLICATIONS 1,398 CITATIONS

SEE PROFILE 


\section{Examining the feasibility of a Smart Region approach in the North West Atlantic and Borders Region of Ireland}

\author{
Niall Ó Brolcháin \\ Insight Centre for Data Analytics \\ National University of Ireland, Galway \\ Ireland \\ niall.obrolchain@insight-centre.org
}

\author{
Adegboyega Ojo \\ Insight Centre for Data Analytics \\ National University of Ireland, Galway \\ Ireland \\ adegboyega.ojo@insight-centre.org
}

\author{
Lukasz Porwol \\ Insight Centre for Data Analytics \\ National University of Ireland, Galway \\ Ireland \\ lukasz.porwol@insight-centre.org
}

\author{
David Minton \\ Northern and Western Regional Assembly \\ Ballaghaderreen, County Roscommon \\ Ireland \\ dminton@nwra.ie
}

\author{
Clodagh Barry \\ Western Development Commission \\ Ballaghaderreen, County Roscommon \\ Ireland \\ clodaghbarry@wdc.ie
}

\begin{abstract}
Research and innovation of the smart city concept is logically evolving and extending into the conceptualisation of smart regions. Within the European Union the political priorities and principles are aligning to encourage the development of smart regions. Current plans for jobs, growth and investment, the digital single market, energy union and democratic change align with the long-standing principle of subsidiarity, the circular economy approach [2] and with smart specialisation strategy [3]. This paper examines the ongoing process of engagement and active participation of stakeholders using the quadruple helix model [5] in the conceptualisation, design and implementation of Smart Regional Policy in the Northern, Western and borders region of the Republic of Ireland in an area including 10 local authorities. This process is known as the Smart Places Region initiative.
\end{abstract}

\section{CCS CONCEPTS}

- Social and professional topics $\rightarrow$ Government technology policy

\section{KEYWORDS}

smart region, smart city, egov, governance, smart specialisation, policy, regional government, circular economy, quadruple helix

\section{ACM Reference format:}

<keep blank / do not remove>. 2018. <keep blank / do not remove $>$. In Proceedings of the $11^{\text {th }}$ International Conference on Theory and Practice of Electronic Governance, Galway, Ireland, April 2018 (ICEGOV'18), <keep blank / do not remove> pages.

DOI: <keep blank / do not remove>

\section{INTRODUCTION}

Smart regions are the logical extension of the smart city concept. After all, a city doesn't exist in isolation. EU policy objectives are facilitating this evolution. This paper examines the Smart Places
Region initiative and the feasibility of creating a smart region in the nine mainly rural and sparsely populated Irish counties of Cavan, Clare, Donegal, Galway, Leitrim, Mayo, Monaghan, Roscommon and Sligo. It aims to build the responsiveness of the regional economy to take advantage of modern, new and transformative global trends in the context of EU regional policy.

Some of the innovative solutions referred to in this paper, already exist in the region, across energy, healthcare, industry, commerce, communities etc. The regions entrepreneurs are globally recognised for research, innovation and technology. Convergence between industry, government and state bodies illustrates numerous examples of 'smart solutions'. However, no clear policy or structure currently exists to link these potentials into a fully functioning Smart Region. Phase 1 of the initiative examines the feasibility of such a proposition.

This paper looks at the Smart Places Region initiative which was conceived by the Northern and Western Regional Assembly (NWRA) ${ }^{1}$, the Western Development Commission (WDC) ${ }^{2}$ and the Insight Centre for Data Analytics ${ }^{3}$ at the National University of Ireland, Galway ${ }^{4}$. The initiative aims to bring together the public sector, the private sector, the academic sector and communities within the region using the Quadruple Helix model [5]. The focus is on citizens, academia, social partners, NGO's, public authorities, businesses including SMEs, start-up companies, business organisations, creative sectors, sporting organisations and social entrepreneurs.

\section{Organisation of this paper}

This paper looks initially at the background to Smart Regions, their characteristics, the policy context and the Irish context leading to the establishment of the Smart Places Region initiative. It goes on to describe the methodology used to survey stakeholders within the region leading on to an examination of the results at a stakeholder workshop that analysed them in detail

\footnotetext{
${ }^{3}$ www.insight-centre.org

${ }^{4}$ www.nuigalway.ie
}

${ }^{1}$ www.nwra.ie

${ }^{2}$ www.wdc.ie 
categorising the priorities by carrying out a SWOT analysis. This is then discussed before we finally reach our conclusions.

\section{BACKGROUND}

\subsection{Characteristics of a Smart Region}

The Quadruple Helix Model [5] outlines a partnership between the 4 sectors, Academic, Public, Private and Community. All findings suggest a bottom up approach to developing a Smart Region involving the various actors in a Quadruple Helix model. According to an article entitled Making Smart Regions Smarter ${ }^{5}$ [1] by Markku Markkula the President of the European Union Committee of the Regions (CoR) and Hank Kune Director of Educore BV and Founding Partner and member of the governing board of the Future Center Alliance, the following questions, each bring a specific exploration focus for orchestrating regional innovation ecosystems:

1. Actors: How does cooperation between universities, industry, and public administration function in the region?

2. Structures: Structures, networks, research groups, and jointly steered organisations emerge at the interfaces of collaboration. What is their status?

3. Premises: What premises are available for physical, virtual, and social development?

4. New organisations: New actors often represent hybrids that integrate elements from different institutions, such as science parks and corporate and technology incubators. Have new actors emerged in the region?

5. Knowledge, technology transfer and co-creation: How do the different innovation, invention, and patent services within universities and research institutes, knowledge-intensive business services (KIBS), incubators, and investor organisations function?

6. Policies: Are new financing instruments, collaboration support, intellectual property right measures, and reforms, taxation or regulation in place?

7. Participation: What role does the knowledge base and expertise of engaged citizens play in making the regional innovation ecosystem smarter?

They identified that all innovation hubs, which are also innovation ecosystems, have four factors in common:

1. They have globally valued special expertise and corporate activities based on this expertise.

2. They create new knowledge that is applied on a global scale.

3. The hub attracts international expertise, competence-driven business and investments.

4. They have companies of excellence that operate both locally and globally.

In terms of the Smart Places Region, the following definition was adopted by the partners involved.

Definition of the Smart Places Region

A high-tech intensive and advanced approach connecting people, information, governance and policies using new technologies to create an efficient, clean, energy secure, sustainable, eco-friendly, competitive and innovative region with an enhanced quality of life.

${ }^{5}$ www.timreview.ca/article/932

${ }^{6} \underline{\text { www.ec.europa.eu/regional_policy/en/conferences/smart-regions/agenda }}$
The European Commission's program for research and innovation strategies for smart specialisation (RIS3) is discussed elsewhere in this document. The following quote is from Walter Deffaa, the European Commission, Director-General for Regional and Urban Policy ${ }^{6}$, where he looks beyond the silo approach towards the development of a Smart Region.

Smart Specialisation [3]

"Smart Specialisation is one of the key innovations of the new programming period 2014-20 for European Structural and Investment Funds. It's about creating a new growth dynamic and a transformation of the EU economies. Linking up the Smart Specialisation Strategies between regions in related areas can create additional growth potential beyond the silo approach."

Walter Deffaa, European Commission, Director-General for Regional and Urban Policy.

\subsection{International and European Context}

Smart cities are now fairly commonplace around the world whereas smart regions are only beginning to emerge, in particular because of the European Commission's program for research and innovation strategies for smart specialisation (RIS3) ${ }^{7}$. Probably the best documented example of a smart regional approach is the Helsinki Smart Region in Finland ${ }^{8}$.

The key aspects of Smart Regions are examined by Markku Markkula and Hank Kune [1]. They argue that it is the active orchestration of the regional ecosystem around concepts such as knowledge co-creation and exploitation, opportunity exploration, and capacity building that make a region smarter. They suggest the development of a well-orchestrated regional innovation ecosystem with a strong "smart specialisation strategy" that leverages the role played by universities.

In summary, the conclusions that they draw are as follows:

1. A collaborative, co-creative approach involving all societal actors is required. This approach also includes new opportunities to involve universities as collaborators.

2. The direct involvement of stakeholders from industry, universities, and the public sector, and the engagement of citizens in co-creative work processes, is a prerequisite for the success of smart regions. Through their active roles in the creative translation of potential into practice, universities are essential for infusing the region with knowledge.

3. In order to thrive, regions require the development of attractive places to work and live - and an enabling factor is experimenting with the regional concept of innovation platforms to address their smart specialisation spearheads. In the regional innovation ecosystem, all actors can use the research and innovation base of universities for producing services and other products.

4. A university's capacity to reach out to regional business and the community will fail if the region does not have sufficient capacity for in place innovation. Knowledge creation, dissemination, and use are essential for keeping regions smart.

\footnotetext{
${ }^{7}$ http://s3platform.jrc.ec.europa.eu

${ }^{8}$ www.helsinkismart.fi
} 


\subsection{EC Smart Regional Policy}

The European Commission regional policy focuses on smart specialisation (RIS3). This is a strategic approach to economic development through targeted support to research and innovation (R\&I). Each region, whether it be strong or weak, high-tech or low-tech, goes through a transformative process which involves:

- Developing a vision for growth

- Identifying its competitive advantage

- Setting strategic priorities

- Making use of smart policies and actions

Research and innovation strategies for smart specialisation (RIS3), will be the basis for investments in R\&I under the European Structural and Investment Funds (ESIF) for the 2014-2020 period. The goal is for Europe's innovation investment agenda, which is crucial for achieving growth and competitiveness, to be the result of a collaborative effort among public authorities, stakeholders and the private sector. Successful investment needs to build on each region's strengths and potentials, rather than financing projects indiscriminately and risking a duplication and fragmentation of investments. This can be achieved by creating region-specific smart specialisation strategies.

EC regional policy has a strong impact in many fields. Its investments help to deliver many EU policy objectives and complements EU policies such as those dealing with education, employment, energy, the environment, the single market, research and innovation.

Regional Policy provides the necessary investment framework to meet the goals of the Europe 2020 Strategy $^{9}$ for smart, sustainable and inclusive growth in the European Union.

The five targets for the EU in 2020 are:

1. Employment: $75 \%$ of 20 - 64-year old's to be employed

2. Research \& Development: $3 \%$ of the EU's GDP to be invested in R\&D.

3. Climate change and energy sustainability: Greenhouse gas emissions $20 \%$ (or even $30 \%$, if conditions are right), $20 \%$ of energy from renewables, $20 \%$ increase of energy efficiency

4. Education: Reducing rates of early school leavers below $10 \%$

5. Fighting poverty and social exclusion: At least 20 million fewer people in or at risk of poverty and social exclusion

Specific policies ${ }^{10}$ relevant to the above include the following:

Employment and Labour Market Mobility: EU Cohesion Policy [6] invests in employment and long-term growth in Europe. It supports the Europe 2020 strategy [7], which aims to see $75 \%$ of 20 - 64-year old's in employment by 2020 .

Research and Innovation: Sustainable growth is increasingly related to the capacity of regional economies to innovate and transform, adapting to an ever changing and more competitive environment. This means that a much greater effort needs to be put into creating the eco-systems that encourage innovation, research and development (R\&D) and entrepreneurship, as stressed by the Europe 2020 strategy [7] and its Innovation Union ${ }^{11}$ flagship initiative.

\footnotetext{
${ }^{9}$ www.ec.europa.eu/info/strategy/european-semester/framework/europe-2020-strategy_en

${ }^{10}$ www.ec.europa.eu/regional_policy/en/policy/themes
}

Information and Communication Technologies: The development of Information and Communication Technologies (ICT) is vital for Europe's competitiveness in today's increasingly digital global economy. Over $€ 20$ billion from the European Regional Development Fund (ERDF) and Cohesion Fund is available for ICT investments during the 2014-2020 funding period. These investments support Commission action to create a Digital Single Market, which has the potential to generate up to $€ 250$ billion of additional growth.

SME Competitiveness: Small and medium-sized enterprises are vital for the EU's economy, accounting for more than $99 \%$ of European businesses and two thirds of private sector jobs. The European Structural and Investment Funds will make available more than $€ 450$ billion to Member States in 2014-2020 to finance investments for enhancing jobs and growth.

Low Carbon Economy: Cohesion Policy plays an important role in supporting the EU's transition to a low-carbon economy, in line with the Energy Union strategy. For the 2014-2020 funding period, the rules on the European Regional Development Fund (ERDF) required Member States for the first time to allocate a mandatory minimum proportion of the available funding to the low-carbon economy: $20 \%$ of national ERDF resources in more developed regions, $15 \%$ in transition regions, $12 \%$ in less developed regions.

Transport and energy networks: Investments in transport services and infrastructure directly benefit citizens and businesses. Smart mobility, multi-modal transport, clean transport and urban mobility are particular priorities for Cohesion Policy during the 2014-2020 funding period. Cohesion policy also supports investments in infrastructure for smart energy distribution, storage and transmission systems (particularly in less developed regions).

Education and Training: EU Cohesion Policy invests in people's skills and competences, which are crucial for ensuring the longterm competitiveness of Europe. It is also key for promoting social cohesion - helping all citizens to benefit from the more and better jobs on offer.

Social Inclusion: EU Cohesion Policy supports the social inclusion of people with disabilities, younger and older workers, low-skilled workers, migrants and ethnic minorities such as the Roma, people who live in deprived areas, and women in the labour market. It supports the Europe 2020 Strategy [7], which aims to lift at least 20 million people out of the risk of poverty.

\subsection{Irish Context}

In Ireland, the focus to date has been on the development of Smart Cities. In his report to the Department of An Taoiseach [4], Professor Rob Kitchen of Maynooth University outlined the current state of play. He noted that four principal Irish cities Dublin, Cork, Galway and Limerick - have all deployed smart city technologies, though they vary in the scale of rollout and the extent to which they are coordinated through a smart city vision. Professor Kitchen noted that all initiatives are building on top of legacy infrastructure and many decades of social and economic

${ }^{11}$ www.ec.europa.eu/research/innovation-union 
programmes, rather than creating new, from the ground-up initiatives. As such, technologies have to be layered on top of long standing systems and schemes, and be accommodated within or replace existing organisational structures.

Smart Dublin ${ }^{12}$ : is primarily a Smart City initiative, but it does include all four local authorities in the county also covering rural areas. Therefore, it certainly has a regional aspect. Cork Smart gateway on the other hand is very clear that it is a Smart City and Region initiative and includes Cork City and County councils.

\section{The objectives of Smart Dublin are as follows:}

- Provide Better Services - To develop, drive and facilitate public services which are better, easier, more efficient and accessible for citizens.

- $\quad$ Promote Innovative Solutions - To provide new, innovative and better solutions to existing and future challenges which impact our citizens, businesses and visitors.

- Improve Economic Activity - To support regional economic development by helping to create an ecosystem that attracts and provides opportunities for entrepreneurs, investors and businesses, and communicates this to the wider world.

- Increase Collaboration and Engagement - To create effective internal and external collaborations and partnerships with local authorities, other public-sector organisations, academia, external agencies, businesses, citizens and international partners.

They list their benefits at follows:

- Acts as a reference site to validate smart technologies

- Move from research to reality

- Builds a collaboration framework to solve Dublin's challenges

- Delivers more efficient services

- Increased engagement with citizens and service users

- Enhances the quality of life

Cork Smart Gateway ${ }^{13}$ : aims to enhance the reputation of Cork as an attractive place to live, work, visit and invest. A place where public infrastructure and public service provision utilise best in class technology solutions and one which allows all stakeholders to participate in decision making and enjoy an enhanced environment. This initiative will compliment and support the already large number of organisations in Cork who are working on smart solutions to improve the physical realm, from energy conservation to open data. The Smart Gateway has embraced the notion of becoming smart.

Both initiatives have developed strategies. Their visions are a mix of data-driven, networked infrastructure, fostering economic growth and entrepreneurship, and citizen-centric initiatives, with a particular focus on creating more efficient city services, improved transportation flows, tackling flooding, attracting inward investment and encouraging indigenous start-ups and SMEs, open data and civic engagement. forum to allow these organisations to share and collaborate together while also marketing the Cork region as a smart destination internationally.

\footnotetext{
${ }^{12}$ www.smartdublin.ie

${ }^{13}$ www.corksmartgateway.ie
}

The recent launch of the All Ireland Smart Cities Forum ${ }^{14}$ is a new initiative spearheaded by NUI Maynooth. It has the potential to include smart regions as well and may develop into a useful forum for collaboration between Smart Cities and Regions.

\subsection{Current Status of the Smart Places Region}

The Smart Places region as defined in this document is currently at stage 1 of its development. There are many Ad Hoc improvised smart initiatives scattered throughout the region. These have been implemented be individual citizens, companies, organisations, institutions and indeed by the Irish Government. Most examples of consistent or connected Smart initiatives in the region came about because of Government policies. In some cases, these were prompted by the EU and EC. Examples are regional waste management plans, the national spatial strategy, online motor tax services and the online library scheme.

A clear need has been identified in the Smart Places survey carried out for this report for a coordinated approach to align Local, Regional, National and European strategies in order to move the Smart Places Region from Stage 1 through Stage 2 to Stage 3. (See figure 2.5). This should take account of European regional policy which requires a bottom up and inclusive approach.

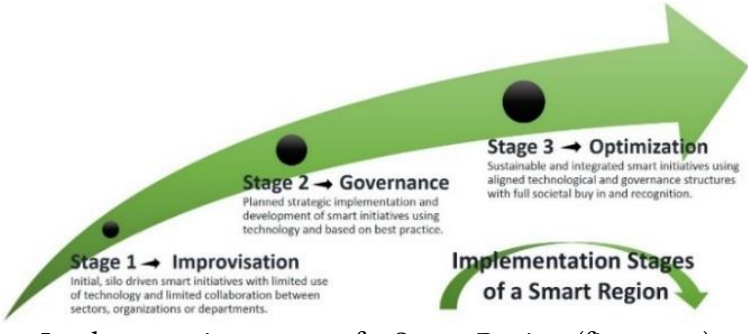

Implementation stages of a Smart Region (figure 2.5)

Policy Development in the Smart Places Region

To date there have been no major policy developments at local or regional level in terms of developing a Smart Places Region. However, this paper examines the Smart Places initiative designed to map the way towards putting in place such policy. The concept of the Smart Places region has been fully endorsed by the Northern and Western Regional Assembly (NWRA) and it also was agreed by the members of the NWRA to bring motions to the local authorities within the region. In terms of research and innovation the Smart Places region has great potential. Many of Irelands largest research centres have a strong presence in the region including, Insight, Remedi and Cúram. While NUI Galway is the only University in the region it is now ranked in the top $1 \%$ in the world and is the only university in Ireland to see its ranking increase significantly in recent years. It has over 17,000 students and very good linkages with industry. It also encourages business development through its Ignite Technology Transfer Office (TTO) commercialisation programme. There are also 3 Institutes of Technology in the region, Galway Mayo Institute of Technology with over 9,000 students, Sligo Institute of Technology with over 6,000 students and Letterkenny Institute of Technology in Donegal with over 3,000 students. These include incubation units for start-up companies as part of the New Frontiers programme in Galway City, Castlebar in Mayo, Sligo and Letterkenny in Donegal.

\footnotetext{
${ }^{14}$ www.smartcitiesireland.org
} 


\section{METHODOLOGY}

\subsection{Smart Places Region Analysis}

Initially an online survey was carried out and supplemented by face to face interviews with key stakeholders from all counties and from the following sectors, academia, community, private and public. While it was open to all comers to respond to the survey on the website, www.smartplaces.insight-centre.org, most respondents were invited directly by email and by direct and indirect social media messaging. Responses were received from across all local authorities in the smart places region. These responses were collated, cleaned and analyzed. The results of this research were supplemented with desk research, including analysis of City and County Development plans and Local Economic and Community Plans from each local authority area. This research was used to inform face to face meetings at a local level and mini workshops.

Finally, a Smart Places Region initiative expert and stakeholder workshop carried out a SWOT analysis to examine the strengths, weaknesses, opportunities and threats in relation to the Smart Places Region. Experts in Smart Governance, stakeholders from across the region and from all four sectors were presented with the results of the survey. The context of the Smart Places Region initiative was then explained. Following on from this, three groups were formed and invited to feed back their opinions in the form of a SWOT analysis. Groups were invited to discuss each aspect of the SWOT for five minutes and then participants were asked to write down their key points individually. When this process was concluded. Groups were asked to select their top answers. These answers were then analysed and grouped together. The results are outlined in section 4 of this paper and discussed in section 5 .

\section{SMART PLACES ANALYSIS}

\subsection{Response to Survey}

All respondents were asked to identify which sector they belong to. The breakdown by sector is outlined below. In terms of sectors, it was a fairly balanced response but there was a slightly lower response from the community sector. In terms of local authority areas Galway City provided the largest response to the survey and County Clare had the lowest response.
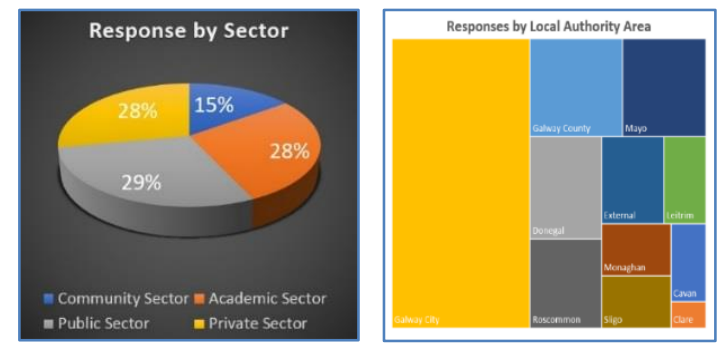

\subsection{Priorities Identified in the Survey}

Smart communities, infrastructure, energy, environment and technology emerged as the key components of a smart region in the Smart Places survey. Respondents were asked to choose their priorities. The most popular priority was smart communities which was interesting as this priority was chosen from people representing all sectors and not just the community sector.

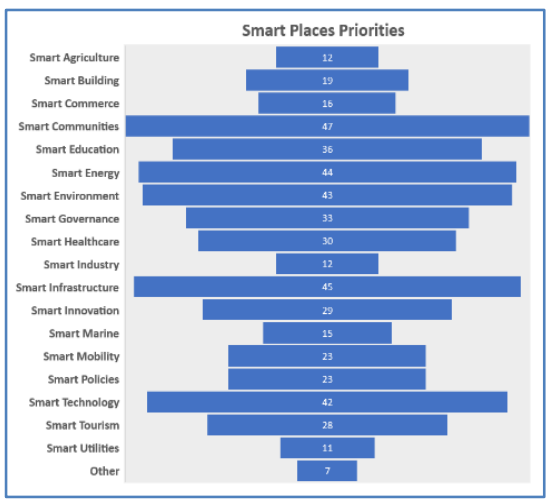

Roughly half of those representing the community sector saw smart communities as a key priority while roughly a third of academics, private sector representatives and public-sector representatives saw smart communities as a key issue.

The availability of fast Broadband was highlighted as an issue again and again in the responses. However, the fact that communities were selected as the most important attribute of a Smart Region is an important finding and clearly shows that citizen engagement at all stages is a priority for many people. There is also a clear understanding that technology, environment and energy are key components of a smart region.

\subsection{Key Findings of the Smart Places Survey}

The survey very much highlighted the importance of people in developing a Smart Region. This is borne out by international experience where the prioritisation of citizen engagement over the immediate introduction of technology in the development of Smart Cities or Regions has been shown to bring much better results ${ }^{15}$. Smart cities such as Barcelona in Spain and Seoul in South Korea have moved to ensure that citizens play a key role in the development of smart initiatives and strategies. It is also clear, both internationally and locally that a smart regional approach (often with the city at the centre) is gaining more traction. Barcelona is a case in point. Cork in Ireland is another very good example of the adoption of the regional approach.

\section{Smart Places Survey - Key Findings}

Prioritisation of citizen engagement over the introduction of technological solutions is a key requirement of all sectors in response to the Smart Places survey.

The Smart Places region has a long way to go in terms of development as a Smart Region. Many respondents believe that the Smart Places Region is falling behind in terms of smart modern solutions.

In terms of infrastructure, the delivery of high-speed broadband and a smart grid are seen as key priorities.

Many respondents see it as essential for local authorities to develop digital strategies that feed into a regional and then a national strategy. Interoperability of resources and data is seen as a priority.

There is a lack of awareness among citizens of many of the smart initiatives that are currently taking place.

People have very broad and often contradictory views of what constitutes a smart initiative. However, most people recognise

\footnotetext{
15 www.bam.co.uk/media-centre/blog/bamblog/2017/01/11/smart-cities-will-evolve-through-citizen-engagement
} 


\begin{tabular}{l}
\hline $\begin{array}{l}\text { that citizens, technology and the improvement of public } \\
\text { services are involved. }\end{array}$ \\
\hline $\begin{array}{l}\text { Many respondents see clean, green and smart as } \\
\text { complimentary to each other. }\end{array}$ \\
\hline $\begin{array}{l}\text { Many respondents do not believe that key institutions in the } \\
\text { region are particularly smart, although others cite initiatives } \\
\text { taken by local authorities, colleges and businesses. }\end{array}$ \\
\hline $\begin{array}{l}\text { At present, there is not seen to be a coherence in terms of smart } \\
\text { policy at local, regional or national level. For governance, the } \\
\text { EU was seen as the main driver of the smart agenda. }\end{array}$ \\
\hline $\begin{array}{l}\text { Many people in the region believe that the region can become } \\
\text { self-sufficient in renewable energy. However, the electricity } \\
\text { grid is seen as a real barrier to achieving that. }\end{array}$ \\
\hline $\begin{array}{l}\text { There are some examples of local authorities co-operating with } \\
\text { neighbours in terms of smart initiatives but other examples of } \\
\text { local authorities not even co-operating between departments. }\end{array}$ \\
\hline $\begin{array}{l}\text { Dashboards, apps, public WIFI, real-time information and open } \\
\text { data were all mentioned in the survey but there is little } \\
\text { evidence of citizen satisfaction with any of these initiatives. }\end{array}$ \\
\hline
\end{tabular}

\subsection{Strengths identified}

The stakeholders group identified the following areas in which the Smart Places region is currently strong:

(1) High quality research and education

(2) Good natural resources (land, water, energy and agriculture)

(3) Community spirit, resilient and safe, strong cultural values

(4) Good collaboration between organisations and communities

(5) Great tourism destinations with potential for growth

(6) Smart resourceful and well-educated people

(7) High quality of life throughout the region

(8) Well established Medtech cluster

\subsection{Weaknesses identified}

The following weaknesses were identified by the stakeholders as part of the SWOT analysis:

(1) Depopulation, diversity and division of the region

(2) Poor infrastructure, especially broadband and transport

(3) Weak governance, lack of regional policy and under delivery

(4) Lack of understanding and poor usage of data

(5) Disparate region with a fragmented organisational approach

(6) Poor levels of awareness of technology and systems

(7) Bad planning and imbalanced regional development

(8) No standardisation within the region

\subsection{Opportunities identified}

These potential opportunities identified by the expert stakeholder group should inform policy for the development of a Smart Region:

(1) Collaborative approach at regional level across sectors

(2) Develop a network of technology hubs and hot desks

(3) Improve broadband and quality of life to attract employment

(4) Better public services via online, open data and IoT solutions

(5) Create a regional sustainable energy framework

(6) Support home working, reducing housing \& traffic issues

(7) Use technology to reduce social exclusion

(8) Develop regional smart transport solutions

\subsection{Threats identified}

The main threats to regional progress and cohesion that the stakeholders group identified are listed below:

(1) Cyber security needs to be robust

(2) Data privacy and citizen trust issues need to be addressed

(3) There is a strong resistance to change at all levels

(4) Lack of funding and investment can be a barrier to progress

(5) Inadequate upskilling, training and education of citizens

(6) Loss of humanity through over use of technology

(7) Internal and external competition can affect progress

(8) Lack of vision, poor governance and unsustainable policies

\section{DISCUSSION}

In this paper we looked at the emergence of smart regions, particularly as a result of EU policy. We looked at the background to Smart Regions, their characteristics, the policy context and the Irish context leading to the establishment of the Smart Places Region initiative. The paper then described the methodology used to survey stakeholders within the region leading on to an examination of the results at a stakeholder workshop that analysed the results in detail categorising the priorities by carrying out a SWOT analysis. The results of the SWOT analysis should inform policy, particularly in relation to the Smart Places Region initiative but also potentially this analysis can form the basis for policy in relation to the development of similar smart region initiatives.

\section{CONCLUSIONS}

It is clear from the research carried out that people in all sectors are broadly in favour of the concept of a Smart Region. However, it is also clear that public consultation at every stage of the process is demanded. Most of the findings point to the fact that people would like to see much greater collaboration by organisations and better decision making facilitated by technological advances. There is however a note of caution. Firstly, people do not wish to lose their valuable sense of community and secondly people are concerned by the potential loss of their privacy and security as a result of data and technology being used inappropriately. Ultimately though people give a cautious welcome to the concept of a smart region and would like to see their lives improved as a result.

\section{ACKNOWLEDGMENTS}

This work was supported by the Northern and Western Regional Assembly (NWRA), the Western Development Commission (WDC) and the Insight Centre for Data Analytics at the National University of Ireland, Galway.

\section{REFERENCES}

[1] M. Markkula and H. Kune, "Making Smart Regions Smarter: Smart Specialization and the Role of Universities in Regional Innovation Ecosystems," vol. 5, no. 10, pp. 7-15, 2015.

[2] "Economics of Natural Resources and the Environment, Chapter 13: The circular economy."

[3] E.- Regio, J. R. C. Smart, and S. Platform, Report on joint EUA- REGIO / JRC Smart Specialisation Platform expert workshop: The role of universities in Smart Specialisation Strategies.

[4] "Getting smarter about smart cities: Improving data privacy and data security."

[5] "Using the Quadruple Helix Approach to Accelerate the Transfer of Research and Innovation Results to Regional Growth.”

[6] C. Policy, "An introduction to $\rightarrow$ What is Cohesion Policy?" no. June 2014.

[7] E. Commission, "E u r o p e 202 0." 